\title{
Characteristics of Chest X-Ray in Patients with Cancer at the Dharmais Cancer Hospital Emergency Room during the COVID-19 Pandemic
}

\author{
Bima Taruna Sakti ${ }^{1}$, Rosalina ${ }^{2}$, Jaka Pradipta ${ }^{3}$ \\ ${ }^{1}$ Department of General Practitioner, Dharmais Cancer Hospital, Jakarta, Indonesia \\ 2 Department of Radiology, Dharmais Cancer Hospital, Jakarta, Indonesia \\ ${ }^{3}$ Department of Pulmonology, Dharmais Cancer Hospital, Jakarta, Indonesia
}

\section{ARTICLE INFO}

Received : 22 February 2021

Reviewed : 01 April 2021

Accepted : 07 June 2021

Keywords:

cancer, chest X-ray,

emergency room

\author{
*Corresponding author: \\ Bima Taruna Sakti \\ Department of General Practitioner, \\ Dharmais Cancer Hospital, Jakarta, \\ Indonesia \\ bimasakti186@gmail.com
}

\begin{abstract}
A BSTRACT
Background: Conventional chest X-ray (chest X-ray) in Dharmais Cancer Hospital emergency room (ER) is still the primary modality to diagnose patients with cancer with dyspnoea complaints. Chest X-ray was also carried out to screen inpatients at the Dharmais Cancer Hospital ER at the beginning of the COVID-19 pandemic in Indonesia. It was essential because patients in the Dharmais Cancer Hospital ER were patients with cancer, with low immunity and a high risk of being exposed to various infections. Thus, the purpose of this study was to determine the characteristics of chest X-rays in patients with cancer at the Dharmais Cancer Hospital ER during the COVID-19 pandemic in February-May 2020.
\end{abstract}

\begin{abstract}
Methods: This was a descriptive study. The population involved was all patients at the Dharmais Cancer Hospital ER who received chest X-ray support, with the inclusion criteria for diagnosing lung cancer, breast cancer, cervical cancer, colorectal cancer, and blood cancer (Leukemia) from February to May 2020. Data analysis employed univariate analysis by utilizing tables and graphs in presenting the data.
\end{abstract}

Results: 289 samples met the research criteria. The highest visits were patients with breast cancer (41.2\%). The most common thoracic images were pleural effusion (34.3\%), followed by bronchopneumonia (31.1\%), normal lung (16.6\%), lung mass (7.6\%), pneumonia (5.2\%), and others $(5.2 \%)$, consisting of atelectasis, bronchitis, fibrosis/chronic pulmonary process, pulmonary emphysema, cardiomegaly, and specific process. Besides, the chest x-ray bronchopneumonia was $31.1 \%$ (90 samples), accompanied by pleural effusion of $44.4 \%$. From the chest X-ray, pleural effusions were $34.3 \%$ (99 samples), with lung cancer being the most common with pleural effusions (48.4\%).

Conclusions: More than $80 \%$ of chest $x$-ray performed in the ER are abnormal. Also, breast cancer is the highest in the Dharmais Cancer Hospital ER cases, with the highest chest $\mathrm{x}$-ray of pleural effusion.

\section{INTRODUCTION}

For nearly half a century after the discovery of X-rays by Roentgen in 1895 , radiological imaging was primarily based on plain and contrast-enhanced radiographs. The images are created by exposing the film to an attenuated X-ray beam after penetrating the body [1].

During the COVID-19 pandemic, the cito chest X-ray examinations at the Dharmais Cancer Hospital emergency room (ER) were carried out on all patients who would be hospitalized for screening for lung infections. It is essential because the patients in the Dharmais Hospital ER are patients with cancer. The symptoms experienced are usually mild and appear gradually. Some people who are infected do not show any symptoms and still feel well.

Chest radiography showed no abnormalities in earlystage COVID-19 infection. Therefore, radiography was not recommended as the first-line modality in screening suspected COVID-19 patient. However, chest radiography 
in mild COVID-19 infections showed local patchy shadows in the outer band and subpleural area of the lungs. Multiple consolidations were found in severe cases, where some fused into large patches, with small amounts of pleural effusion detected [2].

On the other hand, the most common symptoms of COVID-19 are fever, tiredness, and dry cough. Some patients may also experience aches and pains, nasal congestion, runny nose, headache, conjunctivitis, sore throat, diarrhea, loss of smell, and skin rash [3]. According to data from the Ministry of Health of the Republic of Indonesia, as of May 29, 2020 confirmed cases of COVID-19 in Indonesia have reached 25,216 cases, and in DKI Jakarta as many as 7,128 cases [4].

Pneumonia can be defined as consolidation of the lung produced by inflammatory exudate, usually as a result of an infectious agent. Most pneumonias produce airspace disease, either lobar or segmental. Other pneumonias demonstrate interstitial disease and some produce findings in both the airspaces and the interstitium [5].

At the beginning of the COVID-19 pandemic, the SARSCoV-2 rapid test's serological examinations were still very limited in number, and the throat swab examination with real-time polymerase chain reaction (qRT-PCR) SARS Cov2 could not be performed at the Dharmais Cancer Hospital. Thus, to detect an infection in the lung organs early, it was necessary to perform a chest X-ray examination. Based on the prevailing policies at Dharmais Cancer Hospital, if the pneumonia imaging were found, the patient would be treated in a special isolation room for pneumonia infection. Therefore, this study aimed to see a chest X-ray of patients with cancer at the Dharmais Cancer Hospital ER during the COVID-19 pandemic from February until May 2020.

\section{METHODS}

Sources of research data used secondary data on Dharmais Cancer Hospital Health Information System by looking at the research variables recorded in the SIRSKD Dharmais Cancer Hospital. This research employed data in the first quarter since the pandemic was declared.

This research was conducted at Dharmais Cancer Hospital from August until December 2020. The research design employed in this study was descriptive, with the primary objective of seeing the criteria or description of an objective condition. Besides, this research has obtained ethical clearance from the medical ethics committee of the Dharmais Cancer Hospital.

The population used in this study was all ER patients at Dharmais Cancer Hospital from February to May 2020 who had chest X-ray posteroanterior (PA) support and met the inclusion criteria including, 1. ER Patients at Dharmais Cancer Hospital from February to May 2020;
2. Performed chest X-ray examination; 3. Diagnosis of breast cancer, cervical cancer, lung cancer, leukemia, colorectal cancer.

In addition, the variables in this study included gender, patient age, cancer type, and chest X-ray. This study utilized univariate analysis to explain or describe the characteristics of each research variable. The analysis in this study then produced a frequency distribution and percentage of each variable.

\section{RESULTS}

Data collection was carried out since the beginning of August by recording patient data manually who came to the Dharmais Cancer Hospital ER from February 1, 2020, to May 31, 2020. They also underwent cito chest $X$-ray examinations at the ER. The total number of visits made to have cito chest X-ray examination was obtained as many as 536 patients. After that, the existing data were re-selected by including inclusion and exclusion criteria in this study. A total of 289 patient data were obtained with the description of experts included in this study's results.

Table 1 shows that the visits at Dharmais Cancer Hospital ER from February to May 2020 were dominated by female patients (75.4\%) compared to male patients (24.6\%). Based on age categories, most patients were adults or 19 to 60 years old (77.2\%), while less than 19 years old patients were the lowest (18.3\%). The highest type of cancer was patients with breast cancer $(41.2 \%)$, while the lowest was colorectal cancer (8.3\%), comprising colon cancer, rectum cancer, and sigmoid cancer.

Moreover, male patients with the highest diagnosis were lung cancer (63.4\%), and the lowest was the colorectal cancer group (14.1\%). In female patients, the highest diagnosis was breast cancer (54.6\%), whereas the lowest was leukemia (5.5\%) (Table 2). This is in accordance with data from the Global Cancer Observatory in 2018, the highest incidence of breast cancer was with 6,875,099 people [6].

The highest chest X-ray was pleural effusion (34.3\%), and the second-highest was bronchopneumonia (31.1\%) (Table 3). Meanwhile, the lowest was others (5.2\%), consisting of atelectasis, bronchitis, fibrosis/chronic pulmonary processes, pulmonary emphysema, cardiomegaly, and specific process. The most pleural effusion was found in patients with a diagnosis of lung cancer (48.4\%), followed by a diagnosis of breast cancer $(42.0 \%)$ can be seen in Table 4.

This is in accordance with previous research, namely the Overview of Lung Cancer Patients at Dharmais Cancer Hospital (RSKD) in 2008-2012 which was published in 2019, lung cancer cases in male subjects were more common when compared to female subjects with a comparison 3:1 [7]. 
Table 1. Characteristics of patients

\begin{tabular}{lll}
\hline Characteristics & $\mathbf{n}$ & (\%) \\
\hline $\begin{array}{l}\text { Gender } \\
\text { Male }\end{array}$ & 71 & 24.6 \\
$\quad$ Female & 218 & 75.4 \\
Age & 13 & 4.5 \\
$\quad<19$ (child) & 223 & 77.2 \\
19-60 (adult) & 53 & 18.3 \\
$\quad>60$ (elderly) & & \\
Diagnosis & 119 & 41.2 \\
Breast cancer & 62 & 21.5 \\
Lung cancer & 56 & 19.4 \\
Cervical cancer & 28 & 9.7 \\
Leukemia & 24 & 8.3 \\
Colorectal cancer &
\end{tabular}

Table 2. Distribution of cancer diagnosis by sex

\begin{tabular}{lllll}
\hline \multirow{2}{*}{ Diagnosis } & \multicolumn{2}{c}{ Male } & \multicolumn{2}{c}{ Female } \\
\cline { 2 - 5 } & $(\mathbf{n})$ & $\mathbf{( \% )}$ & $\mathbf{( n )}$ & $\mathbf{( \% )}$ \\
\hline Breast cancer & - & 0.0 & 119 & 54.6 \\
Lung cancer & 45 & 63.4 & 17 & 7.8 \\
Cervical cancer & - & 0.0 & 56 & 25.7 \\
Leukemia & 16 & 22.5 & 12 & 5.5 \\
Colorectal cancer & 10 & 14.1 & 14 & 6.4 \\
Total & 71 & 100.0 & 218 & 100.0 \\
\hline
\end{tabular}

Table 3. Distribution of chest X-ray

\begin{tabular}{lll}
\hline Imaging & Count & (\%) \\
\hline Normal lung & 48 & 16.6 \\
Pneumonia & 15 & 5.2 \\
Bronchopneumonia & 90 & 31.1 \\
Pleural effusion & 99 & 34.3 \\
Lung mass & 22 & 7.6 \\
Others & 15 & 5.2 \\
Total & 289 & 100.0 \\
\hline
\end{tabular}

Table 4. Distribution of cancer diagnosis by chest X-ray

\begin{tabular}{llllllll}
\hline \multirow{2}{*}{ Diagnosis } & \multicolumn{7}{c}{ Chest X-ray } \\
\cline { 2 - 8 } & $\begin{array}{l}\text { Normal lung } \\
\mathbf{N}(\%)\end{array}$ & $\begin{array}{l}\text { Pneumonia } \\
\mathbf{N}(\%)\end{array}$ & $\begin{array}{l}\text { Bronchopneumonia } \\
\mathbf{N}(\%)\end{array}$ & $\begin{array}{l}\text { Pleural effusion } \\
\mathbf{N}(\%)\end{array}$ & $\begin{array}{l}\text { Lung mass } \\
\mathbf{N}(\%)\end{array}$ & $\begin{array}{l}\text { Others } \\
\mathbf{N}(\%)\end{array}$ & $\begin{array}{l}\text { Total } \\
\mathbf{N}(\%)\end{array}$ \\
\hline Breast cancer & $15(12.6 \%)$ & $9(7.6 \%)$ & $36(30.3 \%)$ & $50(42.0 \%)$ & $6(5.0 \%)$ & $3(2.5 \%)$ & $119(100.0 \%)$ \\
Lung cancer & $1(1.6 \%)$ & $2(3.2 \%)$ & $22(35.5 \%)$ & $30(48.4 \%)$ & $4(6.5 \%)$ & $3(4.8 \%)$ & $62(100.0 \%)$ \\
Cervical cancer & $11(19.6 \%)$ & $2(3.6 \%)$ & $16(28.6 \%)$ & $14(25.0 \%)$ & $6(10.7 \%)$ & $7(12.5 \%)$ & $56(100.0 \%)$ \\
Leukemia & $12(42.9 \%)$ & $2(7.1 \%)$ & $10(35.7 \%)$ & $3(10.7 \%)$ & $0(0.0 \%)$ & $1(3.6 \%)$ & $28(100.0 \%)$ \\
Colorectal cancer & $9(37.5 \%)$ & $0(0.0 \%)$ & $6(25.0 \%)$ & $2(8.3 \%)$ & $6(25.0 \%)$ & $1(4.2 \%)$ & $24(100.0 \%)$ \\
Grand total & $48(16.6 \%)$ & $15(5.2 \%)$ & $90(31.1 \%)$ & $99(34.3 \%)$ & $22(7.6 \%)$ & $15(5.2 \%)$ & $289(100.0 \%)$ \\
\hline
\end{tabular}

\section{DISCUSSION}

Research has never been done on chest X-rays before, so the authors encountered difficulty finding previous research on chest X-ray data. Based on Riskesdas/basic health research at the Ministry of Health, it is known that the cancer prevalence in the female group is greater than that of men. The prevalence in this group showed an increase in two surveys, from $0.6 \%$ to $2.2 \%$ o for men and $0.74 \%$ to $2.85 \%$ o for women. The difference in prevalence between the genders widened in Riskesdas 2018 compared to Riskesdas in 2013, from 0.14 to $0.65 \%$ o [8].

The highest cancer prevalence was in the age group of 75 years and over in 2013 at 5\%, while the 2018 Riskesdas results revealed that the 55-64-year age group had the highest prevalence of $4.62 \%$. In this regard, various research results uncovered that old age is one of the risk factors for cancer [8].

In addition, the most common cancers suffered by male patients were lung at $16.8 \%$, colorectal at $14.3 \%$, and liver at $10.6 \%$. Most female patients had breast cancer by $34.3 \%$, cervical $19.1 \%$, and ovarian cancer at $7.8 \%$. However, several types of cancer are not sexspecific that attack both male and female patients, including lung, colorectal, thyroid, leukemia, non-Hodgkin lymphoma, and liver [8].

Moreover, the cancer morbidity rate in Indonesia illustrates the same pattern as the world pattern. GLOBOCAN data places lung cancer (2,094 million cases), breast (2,089 million cases), and colorectal (1,8 million cases) with the highest number of cases in the world [6]. 
However, there is a difference between this study's results and the data owned by Pusdatin/data and information center at the Ministry of Health, where the prevalence of colorectal cancer with male patients in the study was lower than leukemia, while other types of cancer such as liver cancer, nasopharyngeal cancer, and prostate cancer were not listed in the study data. It might be due to the inclusion factors in this study, which only took five diagnoses based on the priority of the clinical pathway, and those who entered the criteria for male patients were lung cancer, leukemia, and colorectal cancer. In addition, several factors caused these differences, including the time taken for the study sample and other disease conditions that aggravated the patient's cancer, causing the need for emergency treatment in the ER and chest X-ray performed during visits to the ER at Dharmais Hospital [8].

The pleural space contains a thin film of serous fluid (pleural fluid) that acts as a lubricant between the surfaces. In adults, the normal volume of pleural fluid is between 15 and $20 \mathrm{~mL}$ [9]. An effusion is a collection of fluid in the body where it should not be [10].

Pleural effusions are common and devastating complication of advanced malignancies. Lung and breast cancers cause approximately $75 \%$ of all malignant pleural effusions [11]. Malignant pleural effusions are caused by lung or breast cancer and are diagnosed by analyzing fluid samples taken from pleural effusions through thoracocentesis and from the results of cytological examinations found in cancer cells. Sometimes, more than one sample is needed to find cancer cells [10].

Malignant pleural effusion is also an effusion characterized by the presence of malignant cells. Malignant pleural effusion is a common manifestation in patients with metastatic cancer with an incidence of $15 \%$; the most common is lung cancer, followed by breast cancer, lymphoma, gynecological cancer, and malignant mesothelioma. In addition, there are 150,000 new cases of malignant pleural effusion annually in the United States and 100,000 new cases in Europe. Patients have an overall survival rate of 3-12 months after the initial diagnosis of malignant pleural effusion [12].

\section{CONCLUSIONS}

From the research results, it can be concluded that more than $80 \%$ of chest $\mathrm{x}$-ray performed in the ER are abnormal. In the Dharmais Cancer Hospital ER, breast cancer was the highest case, with the highest chest X-ray of pleural effusion.

\section{DECLARATIONS}

\section{Competing of Interest}

The author(s) declare no competing interest in this study

\section{Acknowledgment}

The author would like to thank the research and development department who helped this research run smoothly in obtaining and processing research data.

\section{REFERENCES}

1. Chen MYM, Pope TL, Ott DJ. Basic radiology. 2nd ed. New York: McGraw Hill Medical; 2011. 396.

2. Jiang ZZ, He C, Wang DQ, et al. The Role of Imaging Techniques in management of COVID-19 in China: From diagnosis to monitoring and follow-up. Med Sci Monit. 2020;26:e924582.

3. Ministry of Health of the Republic Indonesia. Guidelines of prevention and control of Coronavirus Disease 2019 (Covid-19) [internet]. Jakarta: Ministry of Health of the Republic Indonesia; 2020 [Cited 2020 June 2]. Available from: https://covid19.go. $\mathrm{id} / \mathrm{p} /$ regulasi/keputusan-menteri-kesehatan-republikindonesia-nomor-hk0107menkes4132020

4. Ministry of Health of the Republic Indonesia. Current situation of Coronavirus Disease (COVID-19) 30 May 2020 [Internet]. 2020 [cited 2020 Jun 2]. Available from: https://covid19.kemkes.go.id/situasi-infeksiemerging/situasi-terkini-perkembangan-coronavirusdisease-covid-19-30-mei-2020

5. Herring $W$. Learning radiology recognizing the basics. 4th ed. Philadelphia: Elsevier, 2016. p. 14-15, 70.

6. International Agency Research of Cancer. Global Cancer Observatory, Cancer Today [Internet]. International Agency Research of Cancer. 2020 [cited 2020 Jun 2]. Available from: https://gco.iarc.fr/ today/online-analysis-multi-bars.

7. Ramadhaniah F, Khairina D, Sinulingga DT, et al. Distribution of lung cancer patients in Dharmais Cancer Hospital year 2008-2012. Journal of The Indonesian Society of Respirology. 2019;39(1):31-34.

8. Ministry of health of the Republic Indonesia. Pusat Data dan Informasi Kementrian Kesehatan RI: Beban kanker di Indonesia [internet]. Jakarta: Ministry of health of the Republic Indonesia; 2019 [Cited 2020 June 2]. Available from: https://pusdatin.kemkes. go.id/download.php?file=download/pusdatin/ infodatin/Infodatin-Kanker-2019.pdf.

9. Shah PL, Herth FJF, Lee YCG, Criner GJ. Essentials of clinical pulmonology. 1st ed. Boca Raton: CRC Press Taylor \& Francis Group; 2019.

10. West HJ. JAMA Oncology Patient Page. Malignant Pleural Effusions. JAMA Oncol. $2015 ; 1(2): 260$.

11. Patil CB, Gupta A, Gupta R, et al. Carcinoma breast related metastatic pleural effusion: $A$ thoracoscopic approach. Clin Cancer Investig J. 2015;4(5):633-6.

12. Skok K, Hladnik G, Grm A, Crnjac A. Malignant pleural effusion and its current management: A review. Medicina (Kaunas). 2019;55(8):490. 